\title{
Intelligent Engagement
}

\section{I0.I Background}

One of the most fascinating aspects of $\mathrm{CI}$ is the assumption that citizen participation can be the same as citizen expertise. Right after the invention of the Internet, Lévy (1999) claimed the meeting of minds in the online setting could potentially liberate us from the social and political hierarchies that have inhibited humanity's advancement. The Internet allowed for the strengthening of alternative grassroots communities compared to government institutions and corporate interests. Democratic societies could benefit greatly from this new kind of collective intelligence (Lévy, 1999). These ideas were further amplified with the emergence of Web 2.0 a decade ago, offering the vast majority of the population new opportunities to produce knowledge and join in public conversations about their own society. For the first time, people could easily engage in deliberation across national borders and traditional socioeconomic differences. Barriers to artistic expression and civic engagement were removed and people could openly share and connect with each other. Many envisioned the rise of new and prosperous human practices. Most importantly, parts of this new culture honored diversity in a completely new way because race, class, gender, or age was of less importance and individuals were not as constrained because of a lack of financial resources or traditional hierarchies in the offline setting (Jenkins, 2009). It is from this culture and these values that CI gains popularity. For instance, when peer production is described as a core modality of CI, it highlights how individuals increasingly participate in knowledge production activities in open decentralized networks, typically without receiving any economic incentives (Benkler et al., 2015).

In general, most of the large CI projects in this book follow this line of progressive philosophy in its emphasis on open and inclusive participation. Wikipedia was established in these early days of the Internet, back in $200 \mathrm{I}$. Many citizen science projects are open for participants to join without 
having any special expertise or formal qualification. Personal interest is sufficient; age and socioeconomic background do not matter. Even young teenagers have contributed on Wikipedia and FoldIt. The wide outreach made possible by the global online setting increase the likelihood of recruiting more individuals from all over the world. These projects embrace this techno-optimistic participatory culture where everyone, for the first time in history, can share their opinions and knowledge at an unprecedented scale.

However, today one might ask if the citizen expert is just another mythical figure? Will crowd power lead to chaos and the delegitimization of expert knowledge? Although both open science and open democracy are movements that include citizens in new ways, most of the examples in this book are far from mainstream. A decade after Web 2.0 and the high hopes of a better society, there is a strong sense of disillusionment across the globe. The technological optimism has faded away as dark participation is on the rise, along with its echo chambers, trolling, and fake news (Quandt, 20I8). This current "Zeitgeist" stands in sharp contrast to the early days of the Internet when many hailed its potential emancipatory powers.

Still, there are some positive signs, largely scattered around the world. There is more interest in reforming democratic institutions that can involve citizens in new and better ways (OECD, 2020). A key question is how this intelligent engagement can be designed. CI projects look differently in their community structures, indicating that there is no single answer to this question. From one perspective, many of the projects are built around separate individualized work or brief social encounters. A team in an online innovation contest engages in close interaction and collaborative problem solving for a short period. Many individuals are also primarily motivated by economic rewards since they are competing against each other. Both human swarm problem solving and stigmergic problem solving allow individuals to solve problems with a minimum of direct contact. A contributor in a citizen science project may have no contact at all with any of the other participants. Some of the wisdom of crowd approaches are even designed to reduce the amount of social influence. Although social media encourage direct contact and a community structure, an online video platform like YouTube is designed around a much looser community structure between the producers and the subscribers or followers.

The large differences in invested participation, even within one single community, have led scholars to describe social interaction in the online setting in other ways. James Paul Gee (2005), introduced the term "affinity 
space," claiming that online participation was more loose compared with the offline setting. These social structures point to $\mathrm{CI}$ as being centered on individualized work in a "detached networked individualism" (Wellman et al., 2003). A number of CI examples in this book are also built around temporary participation, such as hackathons, Deliberative Polling, and individualized innovation contests.

Mulgan (2018: I02) claims the character of "we" is often missing in much of the literature on CI because of this focus on aggregating separate contributions. Some of the most successful projects like Wikipedia offer evidence of the importance of community norms and the development of solid institutions. The FoldIt community is another example of a citizen science project that is completely dependent on long-term contributors. Most peer production projects also fail if they are unable to attract a community (Benkler et al., 2015). In complex problem solving that require sustained efforts over time, there will usually be a need for an institution or community.

In this chapter, I address several different types of intelligent engagement, with a special emphasis on CI in the political domain. New types of citizen engagement are emerging, such as mass activism, mass voting, and mass deliberation, all considered vital components in a democratic society (Anderson, 2006). In addition, the transparency of the collective work makes new types of asynchronous engagement possible. The final section also discusses various types of dysfunctional engagement that pose a threat towards successful citizen participation.

\section{I0.2 Mass Deliberation}

There are several examples in this book that show how participants with different levels of expertise come together to solve problems together over a longer period. One example is the Polymath project that builds on a collaboration between academics and amateurs with an interest in mathematics (see Section 3.2). Today, there is an increased interest in how the deliberative democracy can be strengthened by utilizing CI. Public authorities are experimenting with ways of involving citizens from the whole population to come together to discuss complex policy problems. A key issue is that participatory governance must be institutionalized as part of permanent decision-making structures in democracies (OECD, 2020).

Citizens' councils, assemblies, and juries are often called "deliberative mini-publics." They typically recruit randomly selected citizens to meet, 
deliberate, and produce informed recommendations to public authorities. Deliberative mini-publics can be implemented in many different ways, and various initiatives demonstrate that there is not just one way of doing it (Chwalisz, 2019). For example, the use of citizen assemblies is gaining popularity. A body formed by citizens deliberates on an issue of local, national, or international importance. Like in Deliberative Polling, the members are randomly selected. Two early examples originate from British Columbia and Ontario, where citizens were assigned to deliberate on a proposal on electoral reform during a period of an entire year. In the case of the British Columbia, the proposal that the citizens eventually made received 57 percent of the vote in the whole population, just below the required 60 percent threshold, even though there were virtually no resources for a campaign before the vote (Fishkin, 2018: I64). Another similar example is the Citizens' Initiative Review in Oregon. A panel of 20 randomly selected citizens are invited to deliberate on a ballot initiative or referendum. They meet for three to five days, both to deliberate and be informed through expert presentations. Then the panel members write a Citizens' Statement that appears in the official voters' pamphlet to every registered voter. The pamphlet intends to be an informed guide and cover the topic of the vote in an objective way (Gastil \& Knobloch, 2019).

Fishkin (2018: 7, 184), the inventor of Deliberative Polling (see Section 4.4), claims we need to transform democracies so everyone can be involved in deliberative activities. Although this type of mass deliberation is still primarily a theoretical idea, there are a few very interesting examples that points towards a new type of democracy. Both the recently established Citizens' Council in Ostbelgien and Better Reykjavík, the participatory governance platform in Iceland, build on the assumption that many citizens can be directly involved in governing a democratic society. These two examples are presented in more detail as they illustrate $\mathrm{CI}$ in the political domain.

\section{I0.2.I Citizens' Council in Ostbelgien}

Today, the Ostbelgien Citizens' Council is regarded as the most advanced example of a permanent deliberative democracy. Nowhere are citizens so consistently involved in institutionalized decision-making systems. Ostbelgien is Belgium's German-speaking community, a separate linguistic region and the smallest federal entity in Europe (Chwalisz, 2019; Van Reybrouck, 2019). In 2019, all parties in the 
parliament of Ostbelgien agreed to form a new democratic institution that would supplement the Parliament and the Executive. Here, the 80,000 citizens would be given a permanent voice. The new democratic institution includes both a permanent institution, the Citizens' Council, and a temporary institution, Citizens' Assemblies or Citizens' Panel, ("The Ostbelgien Model: 2019).

The permanent Citizens' Council is composed of 24 people who participate for a period of 18 months and convene once a month. Members have been selected from three different groups. Six are randomly selected from a previous Citizens' Assembly held in the region, six are politicians - one from each political party; and twelve are randomly selected citizens from the whole population in Ostbelgien. Every six months, eight members are replaced with randomly selected citizens in a rotation system (Cesnulaityte, 2020).

The Council sets the agenda by choosing up to three issues the citizens' assemblies are to work with. In advance, citizens, parliamentary groups, and the government have brought ideas to the Council. In 2019, citizens formulated several of the 20 proposals the Council received. The entire population in Ostbelgien were then allowed to vote on what topics they found to be most important. The council discussed the two most popular topics after the voting round and ended up selecting one topic that the first temporary Citizens' Assembly was assigned to work with (Cesnulaityte, 2020).

Furthermore, the Council decides the size and duration of the temporary Citizens' Assembly. Up to so randomly selected citizens can participate and they must meet a minimum of three times over three months. They can also invite experts to help them learn about the topic. Their role is to produce a recommendation, which is sent to the parliament, who by law are required to debate the issue at least twice and give a detailed response. The Council also monitors the parliamentary debates and ensures that the agreed-upon actions are implemented. Still, the recommendation from the Citizens' Assembly is not legally binding since the Belgian constitution grants all power to the parliament (Chwalisz, 2019).

Any person living in the region can be drafted, if they are more than I6 years old and do not hold political office. The members in both bodies represent the population in terms of gender, age, education, and residence. Those who participate have their costs covered and receive a small honorarium ("The Ostbelgien Model:" 20I9; Van Reybrouck, 2019). 
While Deliberative Polling only involve a couple of hundred individuals, the "lucky winners" of a random sampling process, the Ostbelgien example is interesting as it over time involves a large percentage of the population. In the summer of $2019, \mathrm{I}, 000$ randomly selected citizens were invited in the first round. Ten percent were willing to participate, which was considered a satisfactory response rate. In this final group of roo individuals, participants were randomly selected, controlling for demographic background so it reflected the population of Ostbelgien (Cesnulaityte, 2020).

This rotation system makes it possible to include a wider proportion of the population to participate in democratic decision-making. It is inclusive, but not by letting everybody participate at the same time. Citizens fulfill their civic duty by participating intensely for a short period, knowing that fellow citizens will make similar contributions at another point of time (Chwalisz, 2019). A positive effect of involving a large number of citizens is increased political interest in society as members are likely to discuss political issues with families, friends, and peers. These new democratic systems are to a large degree inspired by how ancient Athens also used rotation and random sampling as core mechanisms in their democracy (see Section 5.4).

It is more uncertain if such deliberative institutions can succeed if applied on a larger scale. Landemore (2020) suggests that major democratic reforms of the representative democracy should build on deliberation by lot and rotation on a massive scale. When citizens are regarded as competent voters, they are challenged to engage more directly in political decision-making. Like in the Ostbelgien example, small deliberative groups like citizen assemblies or other mini-public structures can be given a more prominent position in democracies, "To my mind the deliberative ideal should be, ultimately, 'many connected brains' seamlessly and almost simultaneously exchanging information and arguments in ways that are costless and frictionless, resulting in enlightened individuals and enhanced collective intelligence" (Landemore, 2020). The citizen assemblies are organized as randomly appointed small groups which can deliberate independently of each other. Compared with elections, random selection maximizes diversity and representation from the larger population. Fishkin also proposes a new democratic model that involve both the use of Citizens' Assemblies and Deliberation days where small groups all over the country discuss different political issues through online communication. This type of participation can facilitate powerful learning processes and engagement in societal development (Fishkin, 2018). 
The evaluation from Ostbelgien will be important in further attempts to scale up mass deliberation. It challenges us to rethink both the role of politicians and the relationship between governments and citizens. Citizen assemblies can be used to better connect the voice of the citizen experts with decisions made by elected politicians. The big question is still how these processes can be scaled up in size.

\section{I0.2.2 Better Reykjavik}

Today, a number of local municipalities experiment with governing models that crowdsource citizen ideas on how to improve living conditions. One example is the Santander City brain, an online platform managed by the city council of Santander in Spain, which invites citizens to propose ideas regarding how to make the city better (Ismagilova et al., 2019). Another long-lived online platform is Better Reykjavík. It still provides a continuous dialogue between the local government and the public.

As already mentioned, the economic and politic crisis in Iceland in 2008 triggered Icelanders to begin to experiment with several new types of online participatory governance. There was a massive decline in trust in the existing political institutions. Therefore, the new initiatives focused on letting citizen opinions become more accessible to politicians. Online participatory governance was possible since as many as 95 percent of Icelanders were "regular users" of the Internet and there were few concerns about the digital divide, which was present in most other countries (Lackaff, 20I6).

In 20I0, grassroots activists launched Better Reykjavík as an open innovation platform. Here, citizens could express their ideas and comment on issues regarding services and operations of the City of Reykjavík. From its beginning, the project was "institutionalized," as it was endorsed by a new political party, the Best Party, which won the Reykjavík municipal government election (Lackaff, 20I6). Better Reykjavík evolved from a previous initiative called the Shadow City (Skuggaborg), which was created by grassroots activists shortly before the Reykjavík municipal elections in May 20I0. Each of the eight political parties could use a "branded" section of the site to connect with potential voters, and describe their political priorities so citizens could engage through debate and voting. While most of the parties did not use the site, the exception was the supporters of "anarcho-surrealist" comedian Jón Gnarr's Best Party. This party switched 
the agenda and instead encouraged citizens to help set the agenda by using the site, and approximately I,400 citizens joined.

When the Best Party won the election in 20I0, this created a high awareness of the platform. Consequently, the developers were asked to create a website devoted to soliciting the opinions of the citizens of Reykjavík. Better Reykjavík was opened, and the coalition parties in charge of the city encouraged citizens to use the site to share their priorities for the new government. More than 5,000 users joined the site in this early phase, representing around Io percent of the population who voted at the city election (Lackaff, 2016).

Within months after the launch of the site, several of the highest-rated ideas from the Better Reykjavík site were placed at the top of the policy agenda listed on the Best Party website. The first four years, over 70,000 people participated and discussed over I, 800 policy proposals and ideas. Of these proposals, 450 received formal consideration from the municipal government, and as many as 350 proposals have been implemented (Lackaff, 2016).

If we look at the specific technical features in the platform, it resembles a simplified argumentation map by letting each idea be organized with two columns that invite others to write pro- and contra- arguments on the issue. Ideas can be proposed both in text format and as video presentations. Registered users can both comment on other's ideas or support them by voting, using a "thumbs up" or "thumbs down" rating feature. There is also an aggregate list ordered by the number of votes it has received. Over time, a body of proposals emerges, and each idea can be refined through discussions with other citizens.

Anyone can also view the open forum. Although the municipality will not formally respond to all ideas, a significant number is addressed each month. Each month, a committee in the municipality discusses the toprated ideas. These ideas are considered public property and can be freely used in further policy decisions.

In 20 I2, Reykjavík started using the same site to support its participatory budgeting initiative Better Neighborhoods. The first three years, the city has used nearly USD 8 million to the best ideas submitted for neighborhood improvement. Only residents who live in the neighborhood can cast votes. Because of its sustainability, Better Reykjavík is arguably the most successful example of institutionalized open innovation in an online setting. In 20I4, the Best Party was dissolved, and a new government was formed, but the new parties still decided to continue using the Better Reykjavík platform for the next four years, and the site is still in use today (Lackaff, 2016). 
It raises the question why this initiative has been so successful compared with so many other similar projects that have failed. One important reason appears to be how it rapidly became normalized or institutionalized as a continuous channel for communication between citizens, policymakers, and public administrators. The initiative was implemented quickly; the project attracted a lot of attention. It was given meaningful resources; received both financial and political support. The goals of the project were also clearly defined. Iceland had already much focus on e-government through providing online services to the citizens. In 2013, 96 percent of Icelandic households had internet broadband, and $8 \mathrm{I}$ percent of citizens used e-government services (Lackaff, 2016).

Contrary to other similar projects run by public authorities, the platform is developed and maintained by a grassroots nonprofit organization. Both vTaiwan (see Section I I.3) and Better Reykjavík are unique because the technological innovation come from grassroots activists, hackers, and entrepreneurs, not politicians and government officials. From the beginning, this ensured that key participatory values were part of the project like transparency, accountability, and direct communication between citizens and the government (Lackaff, 2016).

When the City of Reykjavík in 20 I entered into a formal partnership with the Citizens Foundation who maintain the platform, participatory governance was made a mandatory component in the partnership. If the city council wants to use the platform, they have to address the top five priorities posted to the site each month, in addition to the top priorities in each of the 13 topical categories (tourism, operations, recreation and leisure, sports, human rights, art and culture, education, transportation, planning, administration, environment, welfare, various). Consequently, during the years afterwards, tens of thousands of citizens have used the platform, and city committees have formally evaluated hundreds of these citizen-submitted ideas (Lackaff, 2016).

Since the platform is open source, it has very little costs. Disruptive users or trolls have not been a problem, even though the platform is linked to social media networks like Facebook and Twitter. The connection with other social media make it easy for users to more quickly and easily engage in ideas by sharing, commenting, and liking them (Lackaff, 2016).

Better Reykjavík is one example of how citizen expertise is utilized in an online setting. One advantage is that the online deliberation is archived so all individuals do not have to be present at the same time. Asynchronous communication allows individuals to read the same content when it is 
convenient for them and at their own pace, which can potentially lead to greater inclusivity by making the deliberation more convenient. Landemore (2020) claims the online setting offers the potential to solve the longstanding democratic trade-off between group size (direct mass voting on predefined issues) and depth of argument (deliberation and discourse in a small group) for the first time in human history. A range of different communication types can be used, including both asynchronous and synchronous deliberation, verbal online deliberation, in addition to deliberation in an offline setting. In the online setting, activities in the mini publics, like in Ostbelgien, can be made transparent and open for feedback from the larger public.

\section{I0.3 Mass Voting}

In the political domain, another way of utilizing citizen expertise is through mass voting. The most prominent example is how the Five Star Movement ( $5 \mathrm{SM})$, an Italian political party, frequently let party members vote on a range of different issues. The $5 \mathrm{SM}$ was established in 2005 by Beppe Grillo as a grassroots movement against globalization. It recruited activists, mainly linked to left-wing associations, collectives, and NGOs. The five stars in the name refer to the core areas of interest during this period, including public water, sustainable transport, sustainable development, right to free internet access, and environmentalism. Today, the $5 \mathrm{SM}$ has become one of the largest Italian political parties. One important reason is that they attract many disillusioned voters from other political parties by claiming they will bring the citizens back to the center of decision-making process through new types of direct and participative democracy. Their long-term vision is to design a complete political system built around direct democracy, and the party implements similar ideas in the organization of member participation in their online platform.

Another reason why they are popular is their post-ideological approach to politics where policies are determined on an issue-by-issue basis. This ideological flexibility allows the party to address different topics in a strategic way according to new sociopolitical situations. Even the five pillars of the movement (public water, sustainable transport, sustainable development, right to free internet access, and environmentalism), that originally attracted disillusioned voters of left-wing parties from the antiglobalization movement, have gradually become less important, even though they still focus on environmental issues. On particularly important issues, they delegate the decision to online member voting, which is a 
rather unique characteristic among populist parties in Europe (Manucci \& Amsler, 20I8).

Their popularity emerges from a general distrust of other Italian political parties. Since they became the second largest Italian political party in 20 I 3 , the party has gradually become more institutionalized, occupying the center of the Italian political spectrum with its emphasis on "ideological flexibility" (Deseriis, 2017). However, the populist movement has been reluctant to form alliances with other political parties because they have been described as a corrupt group that are only interested in their own privileges (Manucci \& Amsler, 20 I 8). Therefore, the party has not wanted to describe itself as a political party, but instead as a new alternative way of organizing democracy outside of the traditional representative democracy in Italy. The party highlights the active participation of the citizens, and the role of political representatives as being spokespersons of the people. Politics is assumed to be about morality instead of competence, democracy should implement the people's will. When the movement gets Ioo percent support, the citizens become the state and the movement will no longer need to exist (Manucci \& Amsler, 2018).

Consequently, 5SM remains constantly attuned to the people's mood. For example, Europe was not a salient topic for the party until it participated in the elections for the European Parliament in 2014. The metadiscourse about direct democracy is also very important because it brings both left- and right-wing voters together. In order to remain popular, $5 \mathrm{SM}$ aims to capture the current social and political Zeitgeist (Manucci \& Amsler, 2018).

Furthermore, the movement differs from traditional political parties because it does not cost anything to become a member. Nor are there any party congresses because this can lead to the formation of internal factions and strands, and the funding structure is also based on online micro-donations. In addition, there is frequent use of social media communication such as Meetup groups, Facebook groups, and other online groups that aim to replace the physical infrastructure of a traditional political party. This digital democracy seeks to establish a more direct relationship between ordinary citizens and their representatives.

The 5 SM's also has a two-mandate limit for all its elected representatives that intends to prevent the ossification of a party establishment. It resembles the same limitations as in ancient Athens, where citizens could not serve on the same board two times (Deseriis, 2017).

Moreover, the Internet is seen as a transformative technology, which will ultimately undermine the autonomy of the political class, changing the 
political representative to become an executor of the popular body. The free mandate of the politician is criticized, being the cornerstone of representative democracy. Instead, 5 SM introduce direct democracy measures such as online referendums and citizens' initiatives. The utopian vision of this digital direct democracy is nothing less than "the abolition of all political parties." It involves the demise of the professional politician, whose function will ultimately be replaced by the voluntary and temporary participation of all citizens in political life. The constitutive document of the $5 \mathrm{SM}$ also acknowledges the central role of the Internet in expanding participation in the political process. It claims not to be a political party, but instead aims to realize an efficient and effective exchange of opinions and democratic debate outside of associational and political party bonds. Instead, it is assumed that the value intends to be in the totality of the member network users (Deseriis, 20I7).

The online platform Rousseau allows party members to have direct contact with the party in public office and be a part of decision-making processes on several different issues. The platform had I40,000 registered users in 2017 and is currently one of the world's largest online platforms for political participation. Here, members can select candidates via online primaries, vote on the party program, provide feedback to elected representatives on draft legislation, publicize local events, participate in fundraising, and submit their own legislative proposals. Members are repeatedly invited to vote on different sections of the party program (energy, education, foreign policy, labor, defense, and so forth). The members are also consulted on issues such as the expulsion of party members. For example, between 2013 and 2016, I9 Senators and I 8 Deputies have left or have been expelled from 5SM, in accordance with the party's idea that politicians are mere "employees" with a temporary mandate, and who are continually monitored by their employers: the people (Manucci \& Amsler, 2018). In addition, members and councilors can take relevant online courses on how the political system works and they can share experiences with others (Deseriis, 20I7).

The online platform opens up for several functions typical of direct democracy and differs from similar political parties (German Pirate Party, Podemos in Spain) which to a larger degree emphasize deliberative nonbinding processes. In contrast, Rousseau (the online platform) reduces deliberation to a minimum and instead highlights member voting. However, the voting typically consists in filling out single-choice or multiple-choice questionnaires based on expert opinions published on 
beppegrillo.it. Although each expert's blog post receives many comments, the questions are based on the expert's initial opinion, and not on the collective discussion that unfolds on the blog. From this perspective, the $5 \mathrm{SM}$ executive group retains a high degree of control of the party agenda. There are no features in the platform that enable asynchronous communication between the members (Deseriis, 20I7). This platform (Rousseau) is primarily an operational tool for frequent voting. This lack of in-platform discussion tools suggest that Rousseau privileges preference aggregation over processes of opinion formation; decisionmaking over deliberation (Deseriis, 20I7; Manucci \& Amsler, 20I8). Deseriis (2017) claims this hybrid institutional arrangement that enables citizens to participate directly in policymaking does not reduce the autonomy of elected representatives, but on the contrary reinforces it and legitimizes it.

Scholars have struggled to explain what kind of political party MS 5 actually is. One suggestion is that it is a new type of party, build around "techno-populism" as a political philosophy. The basic assumption is that the political competence required for collective problem solving is to be found in the collective intelligence or common-sense knowledge of the citizen-expert. For the first time in history, new technologies make it possible to involve all citizens in democracy. Politics is regarded as "problem solving," which leaves no space for ideological confrontation between rival visions of society. This technocratic conception of politics as problem solving is combined with technological utopianism, which assumes that the Internet will offer a more effective way of mobilizing collective intelligence compared to what can be achieved using traditional political parties. The movement vigorously supports a web utopianism that resembles CI in its assumption that the technological power of the Internet can dramatically improve the problemsolving capacities of human communities. Because it allows for broad outreach and unmediated communication, it can utilize expertise and best practices among dispersed individuals and communities. It is this dramatic increase in CI that in the future will make it possible to solve global problems such as climate change or the economic crisis (Bickerton \& Accetti, 2018).

In the long run, the Internet will eventually lead to a more effective solution of common problems by mobilizing new forms of CI. The main difference from other variants of technocratic discourse is that political competence does not depend on a few entitled experts, but instead, the competence is spread out amongst the population at large, to the crowd. 
By transforming citizens into experts, technocratic and populist elements are combined into a new techno-populist party type (Bickerton \& Accetti, 20I8). The technocratic dimension refers to the assumed existence of only one correct policy solution. Politics is seen upon as "techne" in the original Greek sense, implying that there exists right and wrong solutions to specific policy problems, regardless of partisan attachments. Disagreement is viewed as the result of errors on somebody's part, or self-serving interests at the expense of the common good. Therefore, politics should be designed as an epistemic endeavor in such a way that it increases the probability of finding the correct answers to the collective problems that societies face (Bickerton \& Accetti, 20 I 8).

Finding the right solution is a matter of competence, not ideology. Technocrats, experts, and professionals can replace professional politicians and make the political decision-making process more effective by making it more like how corporations are run. The people should be consulted about the general policy, while experts should implement the policy (Bickerton \& Accetti, 20I8). When there is a particular complex issue, such as the possible withdrawal from the Eurozone, it is first the duty of neutral experts to inform the people about the different options and initiate a collective deliberation. In the second phase, the will of the people is expressed by a purely majoritarian approach (Manucci \& Amsler, 20 I 8).

The importance of competence is also clear from the way the $M_{5} S$ recruits its political representatives. In the 2013 primary elections, candidates were not required to provide a statement of their political views. They only uploaded their CVs because qualifications are what matters. Politicians are "technicians" that are supposed to fix problems. However, this does not only include people with formal qualifications. Grillo famously claimed that if the 5SM was to win the national elections, he would put a housewife with three kids in charge of the Ministry of Finance, not a professor. Grillo's main argument was about competence because the housewife would have a much better understanding of financial issues because of her day-to-day management of her family's finances. It illustrates how citizens with practical knowledge are regarded as the best technocrats (Bickerton \& Accetti, 20I8). This notion of competence echoes the old Athenian democracy, which did not provide any formal schooling to its citizens, but they were still regarded as competent enough to engage in participatory governance systems.

The populist dimension refers to the assumed existence of only one authentic will, which is the will of the people aiming for the "common good" (Bickerton \& Accetti, 2018). However, an obvious limitation is that the 
leadership of the party still formulates the agenda and decides which issues will be set out for mass voting. Some scholars claim that the members still only have a marginal role and that the political philosophy of the movement has not actually been implemented in practice (Manucci \& Amsler, 2018).

Like other anti-establishment parties such as Podemos, 5SM describe the political space as a fight between the "virtuous people" and a corrupt political class. In common with populist parties, the $M_{5} S$ are anti-pluralist as well as anti-elitist. However, the political philosophy is criticized for leaving no room for debate and disagreement. With the strong emphasis on majority voting, one may also ask to what degree minority positions are respected within the party (Bickerton \& Accetti, 2018).

\section{I0.4 Transparent Collective Work}

If we look closer at the different CI practices, we see that transparency is often a basic precondition for collective work. The exception is human swarm problem solving that builds on independent contributions such as innovation contests or crowd averaging methods. Still, many CI projects seek different types of transparency. For example, the transparent knowledge production processes in Wikipedia ensures accountability as different versions of articles are stored and can be retrieved. This transparency makes it easier to settle disputes when interactions are saved. Open online databases also provide a high degree of transparency, by letting everyone get access to the information. The Polymath project save online discussions and make it easier to follow the line of a complex argument. In the first Polymath project, the discussions went over 37 days with full transparency. The storage of the problem-solving process make it possible to analyze the comments at a later point of time (Nielsen, 20II: 202). This transparent environment illustrates how a relatively large group can solve complex mathematical problems through asynchronous communication. The pace of these reflections processes is somewhere in between the qualities of the ongoing verbal discussions in an offline setting and the slow, long-term communication in scientific papers that last for years.

In addition, the transparency of the process provide insight into how scientific knowledge is produced. Outsiders can learn that false starts are a part of the process, and even famous mathematicians struggle and misunderstand issues (Nielsen, 20 I I: 202). However, since so much information is stored, it takes time to examine how knowledge construction processes have evolved, whether it is a Wikipedia article or a collective mathematical argument. 
In the offline setting, the importance of transparent human interaction is connected to productive communities of practice (Lave \& Wenger, I99I). Hackathons are typically organized as transparent offline environments, which provide many opportunities for observational learning (see Section 4.4). For example, one study of hackathons found that it was important that team members were able to collaborate in close proximity to each other in the same room. Then, they can then easily move between different activities, point to visible artifacts, and observe what other participants are doing. Participants learn from others by watching them code or by overhearing issues raised by others in parallel conversations. Whiteboards on the walls are sometimes used to sketch out ideas, make decisions, reflect on alternatives and do informal teaching on how to code. Collaborative writing tools such as wikis were used to make it easy for participants to share lists of software that most people would need during the work. Several participants also took pictures of the images on the whiteboards and later posted them to their team's wiki page. This made it possible to continue with unfinished work after the hackathon was over (Trainer et al., 2016).

A room in a hackathon will typically have both individual workstations and central worktables where multiple people can sit and work. There will also be breakout conference rooms where groups can work privately without distractions. This makes it easier to have impromptu meetings to address important problems. Depending on their interest, participants can flexibly move in and out of different groups at the hackathons (Trainer et al., 20I6).

Hackathons are interesting because they show the importance of a transparent and open environment where both physical and digital tools support co-attention. On a micro level, the transparency of shared visual displays can help a group focus their joint attention towards a problem, whether the informational display is Post-it notes on a blackboard or text written on a laptop screen. Such artifacts can support elaborative collaborative problem solving and transparent group communication, as all parties have access to the same information (Baltzersen, 2017).

One interesting example of transparent dyadic collaboration is pair programming (e.g., eXtreme programming) (K. Beck, 200o). Pair programming is a software development method that lets two programmers do the work by sitting in front of the same screen, but with different roles. The person who is controlling the keyboard and mouse is called the driver, while the other member is the observer or navigator. The driver will write code, while the observer reviews each line of code as it is typed. 
The observer also evaluates the problem-solving strategy (Umapathy \& Ritzhaupt, 2017). Likewise, some solvers in online innovation teams highlight the value of working through a shared interface:

When you are given such a broad challenge, it is hard to know what level of detail to go into and how you want to put it all together. So there was a lot of back and forth work where the document grew and shrunk. It was this process between multiple hands that eventually pruned it down to something that really made sense.

In the online setting, it may be even easier to work on a shared document in real time (e.g., Google documents, Office365). Both chat features and synchronous audio communication offer opportunities for explicit coordination on the same document. However, few CI studies have yet addressed such production tools that influence the collaborative problemsolving process.

\section{I0.4.I Crowd Peer Review}

Another interesting example of transparent collective work in larger groups in the online setting is crowd peer review, an alternative way of doing scientific peer reviews. Instead of doing a traditional peer review with a few reviewers, the editors of a journal invites a group of 50-100 expert reviewers to join the review process (Nguyen, 2018). Even though this is a new practice, there are indications that it can both improve the quality and speed of scientific publishing (Select Crowd Review, 2019). Benjamin List and Denis Höfler first developed the system in the scientific journal Synlett in 2017. In late 2018, Synlett had crowd reviewed I I 5 manuscripts and accepted 70 of them. There are still just a few other journals who have adopted the same method (e.g., SynOpen) (Nguyen, 2018).

The crowd peer review method follows a few specific steps. First, all the potential crowd reviewers receive a notification that a manuscript is waiting to be reviewed. They must then decide if they have the time and expertise to review that specific article. The reviewers who accept the invitation can open the manuscript and write anonymous comments anywhere on the document. They can also see each other's anonymous comments and are allowed to discuss them with each other. Usually, there will be both suggestions and edits in the manuscript after just a few hours. In one crowd peer review example, around is of 80 invited crowd reviewers ended up working on the manuscript (Nguyen, 2018). 
The reviewers will comment on different aspects of the article and also recommend rejection or acceptance. By the time a reviewer starts, the manuscript will already have many comments. The first commenters will usually leave longer comments, while new reviewers are encouraged to simply write "agree" instead of rephrasing the same point. Late reviewers might focus on another part of the paper or the supplementary material. In this way, the review work is split up. One reviewer reports spending one to two hours reviewing each manuscript. Therefore, the reviewers will usually read more manuscripts compared with traditional peer reviewing. The crowd will normally reach an agreement whether to accept or reject the manuscript. Disagreements are communicated politely because all comments are submitted openly (List, 2017; Nguyen, 2018).

On average, the review period lasts two to three days. The editor will then read the reviewers' comments, make the final decision, and send the crowd feedback to the author. A major advantage with crowd peer review process is that the process is much faster. In a traditional peer review, only a few reviewers will write a critique of the paper and this process can take several months, while the crowd review will be completed within a week. Authors appreciate the speedy process. Editors will not have to send reminders to reviewers after the deadlines. Another benefit is the reduced workload for the crowd reviewers. There is also more flexibility because you can simply pass on a manuscript if you are busy (List, 2017; Nguyen, 20I8).

Because of the large number of reviewers, authors will receive more diverse opinions and perspectives from the reviewers. In one experiment, Ioo highly qualified referees were recruited and given 72 hours to respond. The crowd review shows that the authors received more comprehensive and detailed feedback. Overall, the experiment produced a fair and rapid editorial decision. In a traditional peer review with a few reviewers, the comments and arguments will be much shorter (List, 2017; Nguyen, 2018; Select Crowd Review, 2019).

Authors often say that the crowd's comments provide more detailed comments than those from a typical review. One author was surprised that the crowd corrected small errors that even copyeditors would not have discovered. The initial fear was that one might be flooded with responses and miss the comments that really matter (List, 20I7). For example, one author says he once received a 76-page document compiling the crowd's comments on his manuscript and supplementary material. At first, the author was overwhelmed and unsure whether he had to respond to every single critique, but this was not necessary and the author had, overall, a 
positive experience. Regarding the quality of the collective work, a crowd reviewer claims that it reduces the likelihood of unfair or biased reviews that occasionally happen in traditional peer review. When reviewers can read and comment on other reviewers' comments in a transparent online environment, this can reduce bias and lead to better and more accurate reviews (List, 20 I7; Nguyen, 20 I 8).

In the journal Synlett, four-day review periods are typical when weekends are included. The journal SynOpen has also started offering crowd peer review, but with a separate and smaller crowd of about 35 experts. Here, the crowd comments will usually close after two days. Based on the amount of submitted comments, this is considered the best point of time to make decision of whether to accept or reject a manuscript. One day is too short a time period because the reviewers have not yet been able to publish enough substantive comments, whereas four days of reviews can produce too many comments that risk overwhelming the authors (Nguyen, 2018). This mechanism resembles a quorum response in the emphasis on finding the right time to end the process (see Section 4.2).

Moreover, the reviewers seem to enjoy interacting with other peers, rather than just doing the review on their own (List, 2017). In such a transparent environment, one can learn by observing how others do the peer review. In Synlet per 2018, the reviewer group consists of around 80 members. The group of reviewers is more diverse than usual, including scientists in industry, academic faculty of all levels, postdoctoral researchers, research associates, and even graduate students. Graduate students are normally not allowed to review manuscripts, but in this collective process, it is less of a problem to include individuals with little experience who just want to learn how to do a review (Nguyen, 20I8).

A possible disadvantage is that the process may involve more work for the editors and authors. If there are many review comments and suggestions on improvement, the editor must help the author prioritize the most important changes and make a reasonable effort. There is a risk that it may end up being too much work. One of the editors at Synlett was skeptical at first, but is now convinced about the quality of crowd reviewing. In traditional peer review, he would many times face a difficult decision when he received conflicting reviewer recommendations, sometimes with only a line or two of justification. With crowd review, the amount of comments make it easier to grasp the general consensus while disregarding irrelevant comments (Nguyen, 
20I8). However, a crowd report is typically harder to assess than three or four conventional reviews. The editor will therefore have more to read, but not necessarily feel that the workload is too burdensome (List, 20I7).

\section{I0.4.2 The Icelandic Experiment}

Transparent collective work is also becoming increasingly important in the political domain in relation to open democracy. One example is the Icelandic constitutional experiment. In the aftermath of the 2008 financial crash in Iceland, parliament organized a National Forum with 950 randomly selected citizens who were to deliberate and establish the priorities of a new constitution. Openness in the process was essential since it originated from several popular movements in the country that wanted fundamental change in the country. In 20I0, the National Forum gathered for a one-day session with brainstorming and discussions that aimed to bring forward key principles and main ideas that should be included in the constitution. The careful selection of participants legitimized the process as they were considered to reflect the views of the population of Iceland. Many of the participants had no previous experience with politics, but still played an important role in shaping this important political document. Eight themes emerged from the discussions and the results were summarized and rendered into a "mind map" that was also made publicly available (Landemore, 2015 ).

This document served as an inspiration for the work of the Constitutional Council, comprising twenty-five elected members, who were assigned to draft a bill for submission to parliament. The Constitutional Council spent four months in 20I I writing the draft. The direct participation was most prevalent during this period. The 25 members regularly posted online, so the Icelandic people could read the different versions of the draft. In total, I 2 drafts were posted, and anyone interested could post comments and send feedback using social media like Facebook and Twitter, or using regular email and mail. The text was produced progressively, by writing more text, sharing it openly, and then integrating the useful comments. The crowd was self-selected, so there were no mechanisms that could stop trolls or people who would post irrelevant comments. The crowd members also made comments independently from each other and not in collaboration with each other. To some degree, the crowd's comments shaped the 
substance and style of the draft although the details are not described However, the Council would retain final authority over the text. (Landemore, 2015).

In 2012, the draft bill, a nonbinding national referendum on the constitutional proposal was held and it secured a two-thirds approval. However, for different reasons the constitution was rejected by parliament in 2013. Still, the Icelandic constitutional experiment shows how constitution writing can both be more inclusive and transparent. The public was able to witness, observe, and thus make up their minds about the activities of the actors, and the actual drafters of the constitution were able to access the crowd opinion, when they found it necessary. Everything an individual wrote on the Constitutional Council's Facebook page could be viewed, commented on, and ranked (with likes) by other citizens as well. This made multidirectional communication possible. The process took place in the open, which is fundamentally different from traditional constitution writing done by a few selected persons behind closed doors (Landemore, 2015).

\section{I0.4.3 Crowdsourcing Bills of Law}

Another example of transparent collective work is the crowdsourcing of bills of law in the Five Star Movement. A large part of their online platform, Rousseau, is dedicated to lawmaking. Four of the nine platform areas (Lex Members, Lex Region, Lex Parliament and Lex Europe) are dedicated to the drafting and discussion of bill proposals. This crowdsourcing channels a large part of the activity among the party members. Although some activities in lawmaking are left out, such as consulting expert knowledge and prioritizing certain bills, the platform still provides new opportunities for members to interact directly with party representatives (Deseriis, 2017).

If we look more closely at the process, it is divided into distinct phases. In phase one, members are allowed to draft a proposal for a bill of law. It is not only required with a brief description of the bill and of its stated objective, but also an analysis of preexisting Italian legislation on the same subject, and a comparison with similar legislation that may exist abroad. However, many of the proposals do not contain this information and a clear description of the proposal is what matters most, making the threshold of access quite low. Still, only I 7 percent of the 6,223 proposals pass the screening phase, when a member of parliament (MP) assesses whether it meets four requisites: constitutionality, jurisdiction, financial feasibility, 
and consistency. The proposal cannot duplicate or contradict preexisting $5 \mathrm{SM}$-sponsored bills. Consultation is not possible afterwards, which makes the evaluation process unverifiable (Deseriis, 2017).

The next phase is voting. Every two to six weeks, all registered users receive an email that invites them to vote on a new batch of proposals. Each batch will comprise around roo proposals. Still, the voters are only given one day to review the proposals and cast five preferences. The email notification announcing the start of voting is usually just a few hours in advance. This is done because of security concerns, but obviously has a negative effect on the voter turnout, ranging between 12 and I 5 percent of the members (Deseriis, 2017).

The two winning proposals that receive the highest number of preferences move to the tutoring phase. The tutor is an MP who is responsible for transforming a proposal written in a nonjuridical language into becoming an actual bill of law. Once the bill is finished, the MP uploads it to the Lex Parliament area in the platform together with a video presentation of the bill that both includes the original member who proposed the bill and the MP responsible for it (Deseriis, 20I7). The members can then provide feedback on the bill for 60 days. The users have six options when they comment: addition, modification, objection, suggestion, defect of form, and off-topic comments. Members can also rate other comments in this phase (one to five stars), but they cannot reply to other comments. It enables a discussion between the members and the representatives, but not between the members, who alternatively have to use other online environments such as the Beppe Grillo blog, Meetups, or Facebook groups. Still, there is much activity in this phase. From 2014 to 20I7, the 5 SM Deputies and Senators uploaded a total of $324 \mathrm{draft}$ bills, generating more than 70,000 comments (Deseriis, 2017).

No other Italian party has permitted this type of crowdsourcing in draft legislation among its members. However, one of the main challenges in this environment is the lack of feedback on the vast majority of the comments. Although many comments do not require a response, the rate of reply is only 5 percent, and the response rate varies a lot between different representatives. The MPs are supposed to use the most important comments to amend the draft bill, but this interpretation is highly subjective. After the discussions, each MP is also supposed to publish a copy of the revised bill that will be introduced in the appropriate parliamentary committee, along with a conclusive report that explains how comments from the members have been integrated. However, only 23 bills out of 324 
(7.I percent of the total) have reached the publication stage since 2014. The conclusive reports vary a lot in quality and only six of the 23 reports acknowledge how changes have been done based on member comments (Deseriis, 2017).

From a political perspective, the voting processes resembles a traditional wisdom of crowd approach in highlighting the important of making independent decisions. Fractioning and bias are avoided by speeding up the voting process when members are only given a day to vote. This makes it difficult for somebody to start a campaign for one of the proposals. If they are not already well informed on these issues, this may potentially be a weakness. Although the citizens of ancient Athens also just had one day to make their decision, they would still be present and listen to arguments for and against a case before they decided to make a vote. The sheer size of voting on Ioo proposals seems daunting, but the voting design is perhaps built around the assumption that people already know what topics they think are important before the voting (Deseriis, 2017).

However, the last phase in the crowdsourcing process opens up for 60 days of commenting in which members can read each other comments and vote on them. This transparency permits some degree of deliberation. Although the party appears to struggle in responding to all the member proposals, this type of crowdsourcing is still an interesting new way of involving citizens in political decision-making. The political representatives can still choose what bills they want to bring into Parliament. In addition, they will have access to a wide range of opinions from the party members throughout the process (Deseriis, 2017).

\section{I0.5 Social Media Activism}

Citizen activism is important in any democracy. This includes both community volunteering, civic protests, and a free press that is skeptical towards the state power (Anderson, 2006). These two mechanisms highlight collective actions and critical discourse as essential. The online setting opens up new types of informal deliberative discourse through the use of social media. However, most of the social communication is often built around short written messages, for instance on Twitter or Facebook. These platforms offer easy and efficient contact compared with an offline setting, but their potential for deliberation is more uncertain. Although there are significant challenges for informal communication in an online setting, some of the previous examples in this book illustrate how some discuss political issues in new ways. Two such examples are the use of vlog 
(see Section 3.3.I) and memes (see Section 6.5.3). Although the vlog is often used for entertainment purpose, it allows for a personal voice, which can also address political topics. Vlogs enrich the public discourse by providing an alternative publishing channel that can let individuals share their knowledge about uncomfortable and difficult topics that other media have not prioritized (Burgess \& Green, 2018: I27). This can potentially offer other types of deliberative discourse in society. Memes have definitely played a part in political activism and demonstrations. Although countermemes are produced in some cases, the degree of deliberation appears to be limited. The memes primarily reinforce existing political stances rather than promote discussions between groups with conflicting perspectives. The brief format with an emphasis on images and videos is not ideal for citizens who seek deliberation on political issues. The emotional communication can motivate activism and attract other individuals with likeminded opinions. Although memes have engaged the public, there is a risk that the simplicity of the communicative message can amplify extremist attitudes. Since memes often build on intentional manipulation of authentic videos or images, one can also question whether it downplays the truthfulness of information.

Furthermore, an interesting common characteristic with several of the successful knowledge production projects is that they provide meeting places for their members in an offline setting. Several of the most successful projects, like Wikipedia, host regular conferences and workshops in which active members attend to get a stronger feeling of being part of a community. In Wikipedia, there are both local Wiki-gatherings and annual international Wikimania conferences. Although only a very small percentage of Wikipedia contributors attend, these people are some of the most important in the community. At these meetings, like-minded enthusiasts are acquainted, and this makes it easier to maintain contact afterwards.

Another example is from open textbooks, which today are promoted at several offline conferences around the world. At the University of British Columbia, there are now annual conferences about open textbooks. In one recent project (the UK Open Textbooks project), the objective was to adopt US-based open textbooks from OpenStax in the United Kingdom. Hard copies of these textbooks were displayed at conferences, exhibitions, and trade fairs. In addition, a number of workshops were offered at different higher education institutions. These workshops were hosted by the Open Textbook Network, a membership network that connects higher education institutions in their use of OER and open textbooks. One study 
showed that the workshops led 45 percent of faculty participants to adopt an open textbook afterwards (Pitt \& B., 2019).

Moreover, the OpenStreetMap project is built around offline meetings. When Steve Coast presented his work at a conference, he discovered that many more people were interested in joining the project. With time, the joy of meeting other map enthusiasts has resulted in mapping parties where people meet in a physical co-location to go together and gather data (Neis \& Zielstra, 20I4). Studies have also shown that face-to face meetings in open source software development increase participation in follow-up work afterwards (Trainer et al., 20I6). When people are involved in social activities like eating and drinking together, they establish trust and social bonds that are important for online work.

Although online communities can be viable on their own, one can ask if they are sustainable without any offline meeting places. For example, many of the online citizen science projects struggle, and one important reason appears to be a lack of strategy on how to use the offline setting too.

In political activism, there is also a discussion whether it can be built strictly around online activism. In general, online activism can be used in two different ways. On one hand, the Internet can be used to facilitate traditional offline activism strategies like the Arab Spring, which used social media to coordinate street rallies and spread news globally. Over the last decade, the use of Twitter and Facebook have become increasingly important in social movements like the Arab Spring (Murthy, 2013) and Black Lives Matter (Cox, 2017). Another study of mass civil disobedience in Hong Kong's 2014 protests finds that social media strengthened protesters' ability to mobilize and organize, on the Internet and in the streets. Social media were essential for short-term tactical maneuvering and constant information-sharing. However, the social media efforts did not persuade a durable majority of Hongkongers of the movement's legitimacy (Agur \& Frisch, 2019).

In recent years, amateur video clips have become an increasing part of social movements, as people use their mobile phones to record demonstrations and protests as they are unfolding (Germain, 2020). For instance, both protesters and bystanders can now easily record graphic videos of police violence and publish them on social media. Authentic videos provide strongly emotional content that in some cases can trigger larger social movements. The most well-known recent example is the killing of George Floyd, in which a video recorded by a bystander led to worldwide protests against police brutality and institutional racism. It was a I7-yearold teenager who did not know Floyd who recorded what happened. 
She felt she had to document it, but she is still struggling to cope with what happened, and the response to the video on social media, which included a mix of outrage, praise, and criticism. Some accused her for not doing enough to prevent the death, illustrating how tough it can be to publish such videos on social media (Nevett, 2020). If videos of demonstrations are published on social media in totalitarian states, individuals will also be easy to identify by the police.

In addition, activism can be organized only as a virtual activity. However, when people only meet online, it is difficult to build trust, commitment, and long-term interpersonal relationships. Hiding of personal identities and occasional participation may weaken the solidarity between members. The convenience associated with online activism, like distributing petitions without needing to go from door to door, has generated labels such as "clicktivism" or "engaged passivity" that describe a lack of commitment to the cause because members do not physically take part in protest marches. Some studies highlight that social media have led to more dispersed, temporary, and individualized forms of political action, being different from offline activism that typically centers around a single united group who share the same fate (M. Stewart \& Schultze, 2019). For example, by using a hashtag, an individual can experience the feeling of being "part of something larger," without being physically present (Xiong, Cho, \& Boatwright, 2019). Some have argued that this type of minimaleffort activism harms the public sphere in the long run. The e-movements are fragile and create a feeling of togetherness only momentarily, which inevitably dissolves as the algorithms direct attention towards new trending topics. Because members dedicate little time and commitment to a given movement, it is unlikely that a sense of community and solidarity will emerge between them.

Miller (2017), for example, claims that interaction in social media is primarily about achieving communion through passing the word along. Apart from the exchanging of information, it aims to promote social harmony through the maintenance of relationships. The conversational environment is built around limited forms of expressive solidarity. Others claim that online activism offers something new, a more personal and individualized participation, displacing the typical homogenizing processes that emerge through collective action in offline settings. In an online setting, shared experience (e.g., being a racial minority) or collective identity (e.g., a "person of color") is less important, which can also potentially recruit more people to the movement (M. Stewart \& Schultze, 2019). 
What is evident is that contemporary social movements are increasingly hybridizations of both online and offline practices. One interesting example is My Stealthy Freedom (MySF), a social movement protesting the compulsory veiling of women in Iran. It is built around two types of activism, the MySF Facebook (FB) fan page and the, White Wednesdays (WWeds) campaign (M. Stewart \& Schultze, 2019)

The MySF movement began with Masih, an Iranian woman, publishing a photo on her own Facebook page where she was driving a car with her headscarf dropped to her shoulders. On the page, she invited other women in Iran to claim this freedom for themselves. Many responded, and this led here to make the MySF page on FB. The page centers on posting of anonymous photographs of women who have taken their headscarves off in a public place. This illegal act tended to produce powerful emotions including fear, stress, excitement, joy, and pride: "I was walking in the Shariati St. I took off my scarf. I was extremely scared; but I dropped the scarf to my shoulders and started taking selfies" (M. Stewart \& Schultze, 2019). Some women attributed their ability to engage in this risky act to the obligation they felt towards the movement in general and a sense of duty towards Iranian women in general. This imagined solidarity is primarily connected to the production of the courageous hijabless photos on the MySF page. Each member is experiencing the activism by daring to do the same as the other photographers. The shared experience emerges as the members read, like, and comment on the posted photographs. Despite the offline practices of protest being performed individually, the members still felt a strong sense of "we-ness" and collective identity in the online setting, which is often typical of offline social movements (M. Stewart \& Schultze, 2019).

In 2017, after three years, the site comprised around 2,050 photos, with hundreds of comments, likes, and re-shares. At this time, Masih launched a new campaign called White Wednesdays (WWeds). Women were challenged to wear white scarves and clothes in public on Wednesdays to protest against the veiling law. In addition, they were encouraged to capture their experience in short videos talking about their opposition to the compulsory hijab. This made it possible for the members to identify each other in public. Many joined this campaign because they were waiting for the next step (M. Stewart \& Schultze, 2019).

In contrast, the White Wednesday campaign encourage weekly, physical meetings where activists showed their membership by wearing a white headscarf on a Wednesday. The Wednesday offline campaign distinguished itself from the Facebook campaign primarily in that the individual 
activists became identifiable. Fellow protesters could be identified by the white headscarves they wore on a Wednesday. Those who published videos or images on their personal social media pages were identifiable to the whole group. During the five months (May to October 2017) of WWeds's operation, Masih published around 3 IO videos and 120 photos. The campaign's "\#WhiteWeds" hashtag also made it possible for activists to post their content on their own accounts, while maintaining the link to the collective (M. Stewart \& Schultze, 2019).

This led to the development of different subgroups based on where they lived and what opinions they had. Wearing white on a Wednesday was not illegal, and may seem to be a minor practice of resistance, but it still required a considerable commitment to this once a week in everyday life. One would have to engage in repeated face-to-face encounters with family, friends, colleagues, and neighbors, some of whom might support the compulsory hijab. Those who posted videos on their personal social media accounts were likely to be personally harassed, physically threatened, and even arrested. The actions strengthened the individuals' sense of commitment to the protest and the inter-personal bonds between the activists. The activists shared a stronger physically embodied sense of what it is like to protest when the same act was performed many times, and this led to a stronger sense of solidarity (M. Stewart \& Schultze, 2019).

These two types of activism in the movement were highly intertwined: the Facebook page preceded the offline Wednesday campaign, and the offline events were posted on the Facebook page afterwards. This case report illustrates that online social movements do not necessarily lack commitment and can be transformed into offline campaigns too. Online social movements are different because the participation is individualized across different physical places. This allows for more flexible participation, but risks strengthening feelings of loneliness and alienation. As this MySF illustrates, participants will often want to meet offline after some time (M. Stewart \& Schultze, 2019). Compared with an anonymous online mode, campaign mode is much more dangerous because people become identifiable. Even today, the Iranian regime violate human rights by arresting members of the movement and sending them to prison (Alinejad n.d.).

\section{I0.6 Dysfunctional Engagement}

Although positive intelligent engagement obviously is the main interest of $\mathrm{CI}$, dysfunctional engagement that hinder CI also needs to be better 
understood. In the I990s and 2000s, there were high hopes that the invention of the Internet would strengthen democracy and engage citizens in new types of civil debate. Some even expected people to become amateur journalists by publishing their opinions in political blogs, and this would strengthen the critical discourse in society. Among techno enthusiasts, the average user was idealized as a brave new citizen who could produce valuable societal knowledge. In stark contrast, the sharing of information on social media today is typically described as a "private" online behavior that has little interest for societal knowledge production or public news production (Quandt, 20I8).

Although an enormous number of people actively use the Internet, online discussions show few signs of paving the way towards a better and more diverse society. People visit the same websites and prefer to read about just a few topics in the news. Surprisingly, one study even shows that newspaper readership is more concentrated online than offline. One important reason is the search engines that primarily direct attention towards a small number of top news providers (S. Hong \& Kim, 20 I 8). As a result, a tiny number of sites have a large number of readers while very few or none listens to the vast majority of speakers. When many fight for this attention, it has produced the opposite effect of reducing the overall capacity to be heard. Although everyone is equally able to publish content, money is still an important factor. Many professional web producers use sophisticated strategies, like search engine optimization (SEO), to move towards the top of the ranking list because of the market value of reaching a large audience. The web tends to pick a few winners who get all the attention. The popular vote has arguably become even more important, and this has not improved the political dialogue in society (Halavais, 2018).

Because search engines return a lot of information, we spend less time reading the information we find. We skim it and move quickly to the next distraction. The search process pushes us to collect information from more sources, but in far less depth and with few attempts to synthesize the information. Many people also place a lot of informational trust in the top hits on a search engine like Google, equally as much as traditional news media. There is a risk that the convenience of selecting the top hits make us less critical of information. For instance, there are popular delusions among the top ranked results. A search on a question like "Is climate change a hoax?" returns top results that refer to climate skeptics (Halavais, 20I8). The ranking algorithms are concealed in such a way that people are not aware of the manipulation. This can potentially also help political 
parties win elections. In one study, Epstein and Robertsen (2015) found that biased search rankings can shift the voting preferences of undecided voters by 20 percent or more. Young people especially put a lot of trust in the search engines. There is an increased concern that the lack of informational control opens up the possibility of much greater manipulation. Another example is from the 2016 presidential US election, when a firm named Cambridge Analytica were able to develop detailed psychological profiles of American voters based on Facebook data. These were then used to produce a new type of politically inspired behavioral microtargeting that would tailor its pitches and messaging to different personality types (Zuboff, 2019).

Today, many are concerned that these online activities and especially clique formations represent a threat to democracy. The term "filter bubble" typically describes the polarization that social media platforms like Facebook create. Algorithms customize the user's online experience by presenting information that matches previous consumption behavior. The aim is to connect people with information they are likely to want to consume, but the result is that users are placed in a bubble in of personalized stream of content (Pariser, 20I I; Spohr, 20I7). A recent example is how social media amplified opinions about the US election being rigged, which eventually led to the storming of the United States Capitol.

Fake news has become a big problem on the Internet. Another example is how Facebook users in August 2020 were repeatedly spammed with fake posts warning them about the UK's Coronavirus Act. In Stoke-onTrent in the UK, a headteacher even had to assure parents that their children would not be taken away to a secret location if they began coughing in class. Even though the posts were quickly fact-checked, they still circulated and even appeared as an autofill option when searching for "covid act" on Google. It illustrates how difficult it is to remove this kind of content when it first gains a prominent position in online social networks (Greenwood, 2020).

The reason this can happen is because links establish meaning across web pages, but they also make the web "chunky." Once cliques or clusters of websites are established, they tend to reinforce themselves. An individual might find site $\mathrm{A}$ by following a link from site $\mathrm{B}$, and decide to link to both of them because they are similar. This increases the likelihood of a new person finding both site A and B. When looking for a friend or a product, these algorithms are usually experienced as convenient because they help you find friends you might know or products you might like. The feeds provide you with options that are assumed to be relevant (Halavais, 20 18: I02). Filters on Google or the Facebook News Feed are 
prediction engines that constantly try to find out what you want next. Many individuals are not even aware that Facebook News Feed provides a highly customized online experience. This is an advantage when searching for a specific product or service, but it is not what you want in political discourse. Participants will tend to self-assemble into groups that share the same opinions on both Twitter and Facebook. It increases the likelihood of developing more extreme arguments because individuals are drawn towards ideologically homogeneous groups, instead of developing more broadly informed opinions. Most persons also tend to consume media that align with their beliefs and avoid content that has a different perspective. When individuals with the same interests cluster together, there is a risk that these groups become self-reinforcing or self-referential (Halavais, 2018: I02; Spohr, 2017).

Algorithms on social media, like those employed by Facebook, expose participants to information that already supports their existing beliefs. For example, in the 2016 US presidential election, the Facebook News Feed provided widely different information about the candidates depending on whether one was a conservative or liberal voter (Halavais, 20 I 8: I 4I-I 43). In democratic political debate, you do not want a system that amplifies preferences you already have. If groups create their own environments and only read their own news, this leads to a more fragmented discourse and weakens the public agenda. However, empirical studies find that the filter bubbles today have a limited effect on the majority of the population (Zuiderveen Borgesius et al., 2016). Although there are some "echo chambers" that deny factual evidence, like neofascist groups, a large-scale study on Twitter found that the national social network in Australia is highly interconnected, with limited signs of filter bubbles (Bruns, 20I7).

Another major concern is the abundance of fake news in the online setting. Over the last decade, algorithms on social media have tended to reinforce the attention towards some conspiracy theories because of the popular vote mechanisms. People will be curious about reading sensational information even when it is not true, which unfortunately leads some of this content into "winner positions" in the attention economy. Fake news will often also attempt to look like real news, with articles that create the same feeling of credibility as real news. Both images and videos can be manipulated in sophisticated ways. To strengthen the illusion of trustworthiness, there can even be a network of fake sites linked to each other (Tandoc Jr, Lim, \& Ling, 20I8).

Because of social media channels like Facebook, Twitter, and YouTube, it is easy for this type of content to bypass legacy media. Here, anyone can 
become a content producer and spread different types of misinformation, through memes or comments. Traditional news sites will usually have much better opportunities to control the content (Quandt, 20I8). Part of the problem is therefore that social media have increasingly become intermediaries between news publishers and their readers, like the News Feeds on Facebook. All news will then look roughly the same and make it more difficult for users to identify what is fake news. Although thousands of content moderators who work for the company try to remove the offending content, this is a still a constant struggle because of the abundance of misinformation (Zuboff, 2019).

Nevertheless, a large study of 50,000 US users found that the vast majority of online news consumption is still done by simply visiting the home pages of the favorite, typically mainstream, news outlets. While the use of social networks and search engines shows some increase in the mean ideological distance between individuals, these same channels also increase individuals' exposure to material on the less preferred side of the political spectrum (Flaxman, Goel, \& Rao, 20I6).

Still, multimodal disinformation has become an increasing problem in recent years. Studies of Facebook show that people are increasingly interacting socially, with more use of images, GIFs, and emoji instead of words. As previously discussed, political memes reach large audiences on Facebook and Instagram, showing that the visual language of debate is becoming more important. There is no elaboration in this debate, but rather an interaction centered on giving or receiving likes, shares, and brief comments. Likes can be regarded as ideological badges that serve the purpose of marking tribal identification with a group. When information is shared between friends, most people tend to be more positive towards that type of political information (Greenwood, 2018).

Most users avoid debate and serious political comments on Facebook, but it is perfectly okay to share a humorous political meme as a way of entertaining friends or to restate a shared attitude. The result is a culture characterized by "clicktivism," which requires so little effort that is has raised questions whether it tells us anything at all about peoples' actual engagement. Most people find it easy to share something others have made, but they are more uncomfortable in writing something themselves (Greenwood, 2018).

In contrast, some smaller subgroups, like anti-immigrant groups, are highly motivated to write their opinions and will therefore often get a disproportionate attention in social media. It is much easier for extremists to find like-minded people in an online setting compared with an offline 
setting. In one example, an anti-immigrant meme was initially shared by the page of UKIP Brighton \& Hove. Surprisingly, of the 45 people who made comments, a majority were middle-aged grandmothers. These women were also sharing memes about anti-animal cruelty, anti-Black Lives Matter protests, QAnon, anti-BBC proms and content in favor of Brexit. It shows that Facebook content from the UK and the US is intermixed, and it illustrates that if you first share a radical meme, the algorithms give you more of the same, with the risk of luring you into a vicious cycle of increasing levels of radicalization. A slightly racist granny can gradually turn into a "hardcore" racist with a twisted understanding of reality (Greenwood, 2020).

A range of states, political extremists, religious groups, and conspiracy theorists are interested in using the Internet to spread misinformation and propaganda. Even comment sections on established news sites can be targets for both trolls and strategic manipulators because they provide free access to a large audience. One example is how the Guardian identified a high number of manipulative user posts in their comment sections during the Ukrainian crisis. A large number of pro-Russian posts were linked to the Russian government, or at least their support groups in the form of an internet research agency in St. Petersburg. This type of political propaganda can be emotionally loaded, as with trolling, but it is also different because it plans to target specific groups through repeated manipulation over a longer period. Another strategy is the manipulation of journalists to write stories based on fake facts. For instance, this is done by distributing case stories that pretend to be genuine eyewitness reports. Strategic manipulators may also direct an attack towards a specific article, person in the article, or even the journalists themselves. One example is how right-wing commentators in Germany targeted journalists who had written articles about refugees. By writing a massive amount of comments, the goal is to influence the general public opinion about refugees in the whole society (Quandt, 20I8).

To some degree, news sites can control such attacks through user moderation and authenticity checks, but this is far more difficult on social media sites. Although unstructured trolling and cyberbullying still is a problem that follows from the early days of the Internet, it is today the strategic manipulators, not the angry "lone wolfs," who are of greatest concern (Quandt, 20I8).

Most CI projects will to some degree need to cope with the challenge of dysfunctional engagement. Wikipedia solves this both by using bots and content moderators. Others require login on their sites. At a macro level, 
the biggest challenge is perhaps that the large amount of fake news and untrue comments risk creating a general mistrust in the population towards information that may weaken journalism's legitimacy in the long term (Tandoc Jr et al., 20 I8). In addressing this concern, independent fact-checking has been adopted more widely as a strategy to help regain public trust (Brennen, Simon, Howard, \& Nielsen, 2020; Ceci, 2020).

\section{I0.7 Summary}

This chapter points to intelligent engagement through different types of citizen participation. This participation can be organized into two major types of engagement, close and loose engagement. Loose engagement focuses on individualized engagement with little direct contact, while close engagement involves frequent direct contact between participants. The examples suggest that both types of intelligent engagement are equally important, but they need to be carefully designed if they are to be successful.

Loose engagement will typically center on different types of indirect communication and coordination of the collective work. Crowd peer review is one example. The work is usually finished within three days after a certain number of comments have been collected. Flexible participation is important. Only the individuals who have the time and the relevant competence join. Task management is built around self-selection in a selforganizing system. Because the pool of reviewers is large, there will always be enough individuals to do the review. However, the participants will do the work at different points of time within the three days. Because the environment is transparent, comments will build on each other. New reviewers assess the comments that have already been published and identify how they can make new contributions. Individuals contribute with different types of expertise and try to supplement each other in the collective work. The engagement is centered on the work and can be characterized as loose because participants do not communicate directly with each other. When the work is over, the group dissolves and a new group will be established next time. Another example of loose engagement is how the wider public was involved in the work with the Icelandic constitutional experiment. They were invited to send in comments, but they did not receive any direct response from the group writing on the new constitutional draft.

Mass voting is another example of loose engagement. Members in ${ }_{5} \mathrm{SM}$ are primarily invited to vote on different issues and the online 
platform is designed in such a way that it does not allow members to comment on each other posts. The party members vote on many different issues within a short time period to avoid strategic voting, factions, and social influence between members. This resembles a classical wisdom of crowd approach. In the online platform, members can read and learn from other comments, but they cannot discuss issues directly with each other. The disadvantage is the limited deliberation opportunities. Only making simple anonymous contributions such as in citizen science projects might also create feelings of being detached from a community.

However, the Polymath project illustrate that asynchronous participation allows for more flexible participation. Individuals can engage with different levels of intensity in the collective work. Another example is Better Reykjavik, the local municipality initiative that invite citizens to participate by sharing good ideas. The online platform is designed around asynchronous communication, but individuals can respond directly to others' ideas by writing comments. Most users prefer to upvote or downvote different ideas. The voting is important since the local government will respond to the most popular ideas in the platform. This is an example of participatory governance that promote both close and loose engagement, depending on how the citizens want to engage in the platform.

The movement My Stealthy Freedom illustrates how loose engagement gradually was transformed into a close engagement when members increased their activities in both online and offline settings. Individuals in this group displayed varying levels of engagement. Facebook made it easier for the members to support each other, but it also exposed members to greater risk of imprisonment. However, a goal with activism is to seek close engagement, which is a requirement for collective action and longterm political change.

One example that requires close engagement is the Citizen Council in Ostbelgien. In this small deliberative community, participants met frequently and engaged with each other in an offline setting. By getting to know new people with diverse backgrounds, this participation is expected to be both interesting and enlightening. The Council also engages the wider population by inviting the maxi-public to send in proposals on policy issues and vote on the ideas they think are most important. These proposals comprise the basis for the further establishment of citizens assemblies that are assigned to examine how these political problems can be solved. The close link between the mini-public and the maxi-public is 
an interesting institutionalized example of how mass deliberation building on close engagement can be designed.

Most of the examples in this chapter center on citizen empowerment. Both the Ostbelgien citizen council, Better Reykjavík, social media activism on Facebook and the $5 \mathrm{SM}$ share the ambition of wanting to empower citizens. All invite citizens to participate in political action, but in different ways. Even $5 \mathrm{SM}$ have designed crowdsourcing processes around bills of law that are intended to combine both deliberation and voting, although the degree of success appears to be somewhat limited. New channels are being invented that let citizens communicate their concerns more easily and have closer contact with politicians. These votes count, as they comprise recommendations that either the local government or parliament are required to follow up. The rotation system in ostbelgien ensures that a majority of citizens will be invited to participate in government at least once in their life time.

However, there are significant challenges in these systems. Only Io percent of the invited citizens in Ostbelgien choose to participate, which may indicate a relatively low interest in this type of direct democracy. The low numbers also raise concern about how representative these citizen politicians are. Only a small percentage of the $5 \mathrm{SM}$ party members choose to vote on the case-to-case mass voting events that the party holds. This type of self-selection is nearly always unrepresentative and can easily lead to a distorted form of inclusion. Some are empowered more than others are, and special interests or the most vocal can even outperform the majority (Fishkin, 2018: 15). Still, the invitation in these systems is given to many and is built on the notion of equal participation. There is a sense of refreshing openness in these initiatives even though many choose not to participate.

However, from a normative point of view, one can question whether the emergence of techno-populist parties ought to be considered a good thing for democratic regimes. $5 \mathrm{SM}$ highlight majority rule and reject the legitimacy of political opposition with its emphasis on technocratic problem solving. A vital part of democracy is centered on the critical discourse and respect for minority opinions (Bickerton \& Accetti, 20 I 8). 5SM highlights a political life in the online setting with a future ideal built around constant mass voting, but it is far from certain if this is enough for citizen involvement in democracy.

Online activism has been criticized for clicktivism or lack of engagement. The culture of liking and sharing memes on social media risks impoverishing intelligent engagement, and gives growth to echo chambers 
from the sofa at home. Algorithms do not require elaborative arguments. Still, My Stealthy Freedom shows that social media like Facebook can play an important role for people in totalitarian regimes because it is often difficult for such regimes to ban global enterprises that are used for many different purposes.

This chapter points to a number of ways that citizens can be more involved in politics. More of our lives are happening in front of screens, and online engagement is becoming increasingly important. The examples from this chapter show that intelligent engagement can be designed in new ways that utilizes both an offline and online setting.** 